\title{
THE
}

\section{What is the role for metronidazole in the treatment of Clostridium difficile infection? Results from a national cohort study of Veterans with initial mild disease}

\author{
Haley J. Appaneal \\ University of Rhode Island \\ R. Caffrey \\ University of Rhode Island, aisling_caffrey@uri.edu \\ Kerry L. LaPlante \\ University of Rhode Island, kerrylaplante@uri.edu
}

Follow this and additional works at: https://digitalcommons.uri.edu/php_facpubs

The University of Rhode Island Faculty have made this article openly available.

Please let us know how Open Access to this research benefits you.

This is a pre-publication author manuscript of the final, published article.

Terms of Use

This article is made available under the terms and conditions applicable towards Open Access Policy Articles, as set forth in our Terms of Use.

\section{Citation/Publisher Attribution}

Haley J Appaneal, Aisling R Caffrey, Kerry L LaPlante; What is the role for metronidazole in the treatment of Clostridium difficile infection? Results from a national cohort study of Veterans with initial mild disease, Clinical Infectious Diseases, , ciy1077, https://doi.org/10.1093/cid/ciy1077

Available at: https://doi.org/10.1093/cid/ciy1077 
What is the role for metronidazole in the treatment of Clostridium difficile infection? Results from a national cohort study of Veterans with initial mild disease

Haley J. Appaneal, PharmD ${ }^{1,2,3}$, Aisling R. Caffrey, $\mathrm{PhD}^{1,2,3,4}$, and Kerry L. LaPlante, PharmD ${ }^{1,2,3,5}$

1. Infectious Diseases Research Program, Providence Veterans Affairs Medical Center, Providence, RI, United States

2. College of Pharmacy, University of Rhode Island, Kingston, RI, United States

3. Center of Innovation in Long-Term Support Services, Providence Veterans Affairs Medical Center, Providence, RI, United States

4. Brown University School of Public Health, Providence, RI

5. Warren Alpert Medical School of Brown University, Division of Infectious Diseases, Providence, RI

Running title: Metronidazole for mild CDI

\section{Address Correspondence:}

Haley J. Appaneal, Pharm.D., Research Health Science Specialist, Providence Veterans Affairs Medical Center, 830 Chalkstone Ave, Providence, RI 02908, 401-273-7100 ext 4150 (office); haley.appaneal@va.gov

\section{Alternative Correspondence:}

Kerry L. LaPlante, Pharm.D., FCCP, FIDSA, Director of the Rhode Island Infectious Diseases Research Program (RIID), Providence Veterans Affairs Medical Center, 830 Chalkstone Ave, Providence, RI 02908, 401-273-7100 ext 2339 (office); kerrylapante@uri.edu

Keywords: metronidazole; Clostridium difficile infection; Veterans Affairs; mortality; recurrence; predictors

Key summary: In our national cohort of Veterans with initial mild Clostridium difficile infection (CDI) and treated with metronidazole, age $\leq 65$ years was the only predictor of success 30 -days post treatment (absence of 
mortality or recurrence). Among these younger patients with mild CDI, success rates were similar with metronidazole and vancomycin.

Brief 40-word summary: Age $\leq 65$ years was predictive of success (absence of mortality or recurrence 30 days post-treatment) among Veterans with initial mild Clostridium difficile infection treated with metronidazole. Among patients aged $\leq 65$ years, success rates were similar with metronidazole and vancomycin.

\section{Author Contributions:}

Conception and design of the study: $\mathrm{HA}, \mathrm{AC}, \mathrm{KL}$

Data generation: $\mathrm{HA}, \mathrm{AC}$

Analysis and interpretation of the data: $\mathrm{HA}, \mathrm{AC}, \mathrm{KL}$

Preparation or critical revision of the manuscript: $\mathrm{HA}, \mathrm{AC}, \mathrm{KL}$

\section{Potential conflicts of interest disclosure:}

Haley Appaneal is supported in part by a Career Development Award, Department of Veterans Affairs, and has received research funding from Merck. Aisling Caffrey has received research funding from Pfizer, Merck, and The Medicines Company. Kerry LaPlante has received research funding or acted as a scientific advisor for Allergan, Merck, Nabriva, Ocean Spray, Paratek, Pfizer, Tetraphase, and The Medicines Company.

\section{Acknowledgements:}

The views expressed are those of the authors and do not necessarily reflect the position or policy of the United States Department of Veterans Affairs. This material is based upon work supported, in part, by the Office of Research and Development, Department of Veterans Affairs. We appreciate the assistance of Sanja Avramovic, $\mathrm{PhD}$ and Farrokh Alemi, PhD from George Mason University with data generation.

\section{Funding:}


This work was supported, in part, by a grant from Merck. The funding source did not have any involvement in the collection, analysis, or interpretation of data; in the writing of the report; or in the decision to submit the article for publication. 


\section{ABSTRACT}

Background: Metronidazole may still be an appropriate therapeutic option for mild Clostridium difficile infection (CDI) in select patients, but data is limited to guide clinicians in identifying these patients.

Methods: Our two-stage study included a national cohort of Veterans with a first episode of mild CDI (20102014). First, among those treated with metronidazole, we identified predictors of success, defined as absence of all-cause mortality or recurrence 30-days post-treatment, using multivariable unconditional logistic regression. Second, among a subgroup of patients with characteristic/s predictive of success identified in the first-stage, we compared clinical outcomes among those treated with metronidazole compared with vancomycin, using Cox proportional hazards models for time to 30-day all-cause mortality, CDI recurrence, and failure.

Results: Among 3,656 patients treated with metronidazole, we identified 3,282 patients with success and 374 patients without success (failure). Younger age was the only independent predictor of success. Age $\leq 65$ years was associated with an odds of success 1.63 times higher (95\% confidence interval [Cl] $1.29-2.06)$ than age $>65$ years. Among 115 propensity-score matched pairs $\leq 65$ years of age, no significant differences were observed between metronidazole and vancomycin (reference) for all-cause mortality (hazard ratio [HR] 0.29 , 95\% Cl 0.06-1.38), CDI recurrence (HR 0.62, 95\% Cl 0.26-1.49), or failure (HR 0.50, 95\% Cl 0.23-1.07).

Conclusion: Among patients $\leq 65$ years of age with initial mild CDI, clinical outcomes were similar with metronidazole and vancomycin. These data suggest metronidazole may be considered for the treatment of initial mild CDI among patients 65 years of age or younger. 


\section{Word count: 2,989}

\section{BACKGROUND}

Clostridium difficile has become the most common cause of healthcare associated infections in the United States.[1] For over three decades metronidazole has been the mainstay of treatment for initial cases of mild to moderate Clostridium difficile infection (CDI).[2] Until recently, metronidazole was recommended as the first-line treatment option over vancomycin for initial cases of mild-moderate CDI.[2, 3] In early 2018, updated clinical practice guidelines from the Infectious Diseases Society of America (IDSA) and the Society for Healthcare Epidemiology of America (SHEA) were released, which no longer recommend metronidazole for initial nonsevere CDI as per previous guidelines from 2010.[2, 3] Updated guidelines only distinguish severe disease from non-severe disease (previously defined as mild-moderate disease), and 2010 guidelines do not distinguish between mild and moderate disease.[2, 3]

This substantial change in non-severe CDI treatment recommendations is largely based off evidence demonstrating better outcomes associated with vancomycin as compared to metronidazole in patients with severe CDI.[4, 5] Among patients with mild CDI, several studies have demonstrated no difference between vancomycin and metronidazole for mortality, CDI recurrence or clinical cure.[4-6] When metronidazole is used per $2010 \mathrm{CDI}$ guidelines in certain patients with mild-moderate disease it may still have similar effectiveness to vancomycin. Metronidazole is less expensive and may be associated with lower colonization and/ or development of drug-resistant organisms compared with vancomycin.[7, 8]

Since publication of the updated guidelines, expert correspondence has recommended continued consideration of metronidazole as a first-line option for patients with mild CDI and a low risk for disease complications.[8] Limited data exists to guide clinicians in identifying in which patients metronidazole may still be used. As such, first we sought to identify independent predictors of success (defined as absence of mortality or recurrence) among a national cohort of Veterans with mild CDI treated with metronidazole per 2010 CDI guideline recommendations. Then, we sought to compare the effectiveness of metronidazole with vancomycin in patients with mild CDI. Characteristics associated with success were used to identify the subgroup for our comparative effectiveness analysis. 


\section{METHODS}

\section{Study Population}

A cohort of Veterans with a first CDI episode (defined as a stool sample positive for $C$. difficile toxin(s) and $\geq 2$ days of CDI treatment) from May 1, 2010 to December 30, 2014 was used.[9] CDI episodes from inpatient and outpatient settings from 125 VA centers nationally were included. Only patients with mild disease (defined as a white blood cell count (WBC) $\leq 15 \times 10^{3} / \mu \mathrm{L}$ and a serum creatinine (SCr) was $\leq 1.5 \mathrm{mg} / \mathrm{dL}$ within 7 days of CDI treatment) and those treated per guidelines (10-14 days of monotherapy with oral metronidazole or oral vancomycin) were included.[2] Patients with missing WBC or SCr were excluded.

\section{Study Design}

We conducted a two-stage analysis among our large national cohort of Veterans with mild CDI, first conducting a predictive analysis and second a comparative effectiveness analysis.

\section{Predictive Analysis.}

We compared patients with and without successful outcomes with a mild first CDI episode treated with metronidazole monotherapy. Patients with success were those who did not die or have a CDI recurrence at day 30 , and patients without success were those who died or had a CDI recurrence within 30 days post-treatment (failures). CDI recurrence was defined as another CDI positive stool sample or CDI diagnosis code (008.45) and at least two days of subsequent CDI treatment at least 14 days after the initial positive stool sample and within 30 days post-treatment of the initial episode. Our a priori definition of recurrence was a subsequent episode within 30 days post-treatment, as recurrence risk is greatest within 10 days post-treatment and in clinical trials recurrence is commonly defined within $28-30$ days post-treatment.[10,11]

Predictors assessed are presented in Table 1. Treatment setting (acute, long-term care, or outpatient) was defined based on patient location at the time of positive stool sample. Comorbidities were identified using International Classification of Diseases, $9^{\text {th }}$ Revision (ICD-9) diagnosis and procedure codes within the one year prior to the first CDI episode or during treatment. The Clinical Classifications Software of the Agency for 
Healthcare Research and Quality and previously described disease categorizations were used to group specific diagnoses and procedures into broader disease state groups.[12, 13] ICD-9 codes were also used to identify previous and current infections and other acute events. Comorbidity burden was assessed using Charlson comorbidity index and Elixhauser score. All medication exposures were defined as binary variables and windows of exposure were selected based on clinical relevance or previous work.[14-16] Inpatient and outpatient pharmacy data were utilized to determine all medication exposures and CDI treatment duration. Hypervirulent strain was defined as presence of NAP1/027 where strain type data was available and not hypervirulent/unknown strain in the absence hypervirulent strain type or where strain type was missing. Overall, 45 potential predictors were selected a priori and assessed.[2, 14, 17-19]

\section{Comparative Effectiveness Analysis.}

In the second phase of our study, we conducted a comparative effectiveness analysis of metronidazole versus vancomycin on outcomes among Veterans in a select subgroup of our mild CDI cohort. We used characteristic/s predictive of success with metronidazole identified in the first stage of our study, to select the subgroup to compare clinical outcomes with metronidazole and vancomycin. The primary exposure of interest was CDI treatment (metronidazole or vancomycin). The outcomes of interest were 30-day all-cause mortality, 30-day CDI recurrence, and a composite failure outcome (lack of success as defined above). Numerous covariates, which may confound the association between CDI treatment and poor clinical outcomes in patients with CDI, were identified and measured a priori based on underlying causal beliefs.[2, 14, 17-19]

\section{Statistical Analysis}

Predictive Analysis.

We used backwards, manual, stepwise unconditional logistic regression to identify independent predictors of success among patients with a mild first CDI episode treated with metronidazole.[20] Variables from univariate analysis with a $p$-value of $<0.10$ were included in subsequent multivariable analysis and removed one-by-one from the multivariable model until all remaining variables had a $p$-value $<0.05$.[20] Tolerance and variance inflation were used to confirm the absence of collinearity between potential predictors.[20] 


\section{Comparative Effectiveness Analysis.}

Propensity-score matched Cox proportional hazards models were used to quantify the effect of vancomycin versus metronidazole on time to 30-day all-cause mortality, CDI recurrence, and failure among a subgroup of patients with characteristic/s associated with metronidazole success.[21] Propensity scores were developed for exposure to metronidazole compared with vancomycin as function of all potential confounders which was modeled using logistic regression.[21] The predicted probability of exposure for each patient (propensity score) was estimated using this model. We assessed common support (overlapping distributions of the propensity score between exposure groups) using visual comparison.[21, 22] We performed nearest-neighbor 1:1 propensity score matching within 0.01 caliper. To assess balance of potential confounders, standardized biases (absolute standardized difference in means) were examined for the original and matched samples.[22] Crude and matched hazard ratios were calculated using Cox proportional hazard regression models. Cox proportional hazard regression proportionality assumptions were assessed.

\section{RESULTS}

Predictive Analysis.

Among 3,656 patients with mild CDI and treated with metronidazole, we identified 3,282 patients with success at day 30 post-treatment and 374 patients without success (failure). Several significant differences between patients with and without success were observed (Table 1). In multivariable analysis, younger age was the only independent predictor of success identified (Table 2). The odds of success was 1.63 times (95\% confidence interval $[\mathrm{Cl}] 1.29-2.06$ ) higher among patients 65 years of age or younger as compared to those over 65 years of age. There were several predictors of failure identified (odds ratios $<1$, Table 2 ) including: a principle diagnosis of $\mathrm{CDI}$, current intestinal infection, current respiratory failure, malignancy, previous hospital or long-term care exposure, hypoalbuminemia, body mass index $(\mathrm{BMI})>30 \mathrm{~kg} / \mathrm{m}^{2}$, and previous probiotic exposure.

\section{Comparative Effectiveness Analysis.}

For the comparative effectiveness analysis, a mild CDI cohort of younger patients 65 years of age or younger was selected. Predictors of treatment and of failure were included in the propensity score model. Baseline characteristics were well balanced in the propensity score matched cohort (115 matched pairs, Table 3). Among 
the propensity-score matched cohort, no significant differences were observed between metronidazole and vancomycin (reference) for the outcomes assessed (Table 4).

\section{DISCUSSION}

To our knowledge this study is the first to focus specifically on identifying predictors of success and comparing treatment options in patients with an initial episode of mild CDI. This work suggests that metronidazole may still be an appropriate treatment option for younger patients with initial mild CDI.

Age was the only predictor of success identified and may be one of the most important factors when considering which patients with initial mild disease may still be candidates for metronidazole therapy. Several factors may contribute to the increased risk observed in older patients, such as immunosenescence, decreased functional status, and underlying comorbidities.[23] Previous work has demonstrated that older age is an independent risk factor for mortality and recurrence in patients with CDI.[15, 24, 25] Age 65 years or older was among the strongest predictors of all-cause mortality identified in a recent national analysis of adults hospitalized with CDI.[25] A systematic review of 39 studies which assessed the impact of age on treatment failures and recurrence, found higher rates of treatment failures and CDI recurrences in older patients aged >65 years as compared to younger patients (treatment failure: $24.7 \%$ vs. $19.6 \% ; p=0.005$; recurrence: $23.4 \%$ vs 19.4\%; $p=0.003)$.[26] For patients with mild disease it may be important to avoid metronidazole treatment in older patients, however for younger patients metronidazole may still be an option.

Predictors of failure with metronidazole in mild CDI (odds ratio $<1$ ) may indicate patient subgroups where metronidazole should be avoided. Similar to previous findings, a principal diagnosis of CDI (as compared to those hospitalized without a principal diagnosis of CDI or outpatients) was identified as a significant predictor of failure likely related to CDI severity.[9, 27, 28] Previous hospital or long-term care exposure was also a predictor of poor outcomes. The association between CDI and exposure to healthcare settings is well recognized.[29, 30] Within hospital and long-term care settings, the patients are typically older, have an increased exposure to antibiotics and gastric acid suppressants, and environmental exposure to $C$. difficile spores, thus are at an 
increased risk for the development of initial and recurrent CDI.[10] These factors may also contribute to an increased risk for severe disease and mortality.

Factors, such as hypoalbuminemia, respiratory failure and intestinal infection, which may be markers of severe or complicated disease, were also predictive of failure. Underlying comorbidities and hypoalbuminemia are among the most commonly reported risk factors for poor outcomes.[15] While not included in the IDSA/SHEA definitions for severity, hypoalbuminemia is included in other criteria to define severe disease.[5, 31] While antibiotic use was not identified as an independent predictor in our study, antibiotic use is another frequently reported risk factor for poor outcomes in patients with CDI.[15] Patients with comorbid respiratory failure or intestinal infections during a CDI episode may be exposed to non-CDI active antibiotics for these conditions during their CDI treatment. It is also possible an intestinal infection diagnosis may not be due to another infection but may be due to CDI symptoms themselves. Our findings suggest that severe underlying comorbidities and other markers of severity in addition to those of the IDSA/SHEA, particularly albumin level, should be considered when determining which patients have mild disease that can be treated with metronidazole.[31] Continued work is needed to investigate which severity criteria are most useful in defining mild disease that can be successfully treated with metronidazole.

Obesity $\left(\mathrm{BMI} \geq 30 \mathrm{~kg} / \mathrm{m}^{2}\right)$ was also identified as a predictor of failure. Previous work has identified obesity as a risk factor for the development of CDI.[30] There is also evidence that obesity is associated with more severe disease.[32] Among a weighted sample of 22,937 patients with CDI presenting to the emergency department, extreme obesity $\left(\mathrm{BMI}>40 \mathrm{~kg} / \mathrm{m}^{2}\right)$ was associated with an increased risk of in-hospital mortality.[33] The relationship between obesity, severe disease, and mortality is largely unclear at this time, however in general, obesity is associated with increased risk of death compared to normal weight BMI categories.[34] It may be advisable for clinicians to avoid use of metronidazole for mild disease in obese patients.

Among patients 65 years of age or younger, we found no difference between metronidazole and vancomycin for the treatment of initial mild CDI. Existing studies focusing on patients with mild disease are limited. In a single center retrospective analysis of 168 cases of mild to moderate CDI, metronidazole and vancomycin yielded 
similar recurrence rates $(13 \%$ vs. $9 \%, p=0.4)$, however treatment responses were lower for patients treated with metronidazole ( $82 \%$ vs $97 \%, p=0.002$ ).[35] When stratified by strain, a difference in treatment response was only identified among 83 patients with non-NAP1 CDI (78\% metronidazole vs. 98\% vancomycin, $p=0.007)$ while similar rates were observed among 85 patients with NAP1 CDI (86\% metronidazole vs. 97\% vancomycin, $\mathrm{p}=0.13)$. Another retrospective cohort study was conducted in patients with solid organ transplants who had mild to moderate CDI.[36] Similar to our findings, this study found no difference between metronidazole and vancomycin for treatment failure (metronidazole $16 \%$ vs. vancomycin $10 \%, p=0.71$ ), 90 -day CDI recurrence (metronidazole $14 \%$ vs. vancomycin $14 \%, p=0.99$ ), or 30 day all-cause mortality ( 0 in both groups). This was a small, single center study of 71 patients with limited power to detect significant differences. A larger national VA study was conducted among 10,137 patients with a first episode of CDI treated in the VA healthcare system between 2005-2012 that included non-severe and severe CDI.[6] This study demonstrated that in the overall cohort, not stratified by severity, patients treated with vancomycin had a lower risk of mortality versus metronidazole (adjusted RR, $0.86 ; 95 \% \mathrm{Cl}, 0.74$ to 0.98 ) but no difference in the risk of recurrence.[6] Mortality differences observed were largely driven by those with severe disease.[6] In secondary analyses, vancomycin was only associated with a decreased risk of mortality in those with severe disease and not in those with mildmoderate disease (adjusted $\mathrm{RR} 0.91 ; 95 \% \mathrm{Cl} 0.72-1.14$ ).[6] Two randomized controlled trials have also compared metronidazole vs. vancomycin.[4,5] These studies, which did not use IDSA/SHEA criteria to define severity, have consistently demonstrated no difference in small subgroups of patients with mild CDI for recurrence and clinical cure.

There are limitations to our retrospective study. We were interested in assessing guideline concordant treatment thus required a CDI treatment duration of 10 to 14 days per guideline recommendations and that laboratory values be measured to assess disease severity. Our results may not be generalizable to more mild cases that resolve sooner than 10 days or more severe or complicated cases that require treatment longer than 14 days or those in which SCr and WBC were not collected. The VA population consists primarily of older White males and as such generalizability of this study to the general population may be limited. 
Misclassification of outcomes and covariates may impact our results. A priori, we chose to study 30-day CDI recurrence from the end of therapy, because most cases of CDI recur within 1-3 weeks after treatment.[10, 29, 37-39] Moreover, a consensus definition for CDI recurrence has not been established and most previous CDI clinical trials have assessed outcomes at 28-30 days post-treatment.[11] Follow up time among studies assessing risk factors for CDI recurrence have ranged widely from 21-180 days from the previous CDI episode.[16] Misclassification of CDI recurrence that occurred greater than 30 days after treatment is likely. However, the previous national VA study that compared vancomycin and metronidazole assessed for recurrence up to 56 days after the initial CDI diagnosis and similar to our findings found no difference between therapies on risk of recurrence.[6] We only accounted for treatment and care in the VA system, therefore there is the potential that we may of misclassified recurrence in patients who received care for their recurrent episode outside the VA system. Our success and failure outcomes are composite outcomes that include mortality and recurrence and they have not been used previously. We were not able to assess the resolution in CDI symptoms, so composite endpoints did not include treatment failure (continued diarrhea) which is another common poor outcome of CDI.[40] As a consensus definition for CDI-attributable mortality is not established, we measured all-cause mortality. It is possible that some of the deaths we observed were attributable, at least in part, to diseases other than CDI.

In our observational comparative effectiveness analysis, since there was no randomization of patients to either metronidazole or vancomycin, confounding by indication is a chief concern. During the study time period metronidazole was recommended first-line for mild-moderate disease and vancomycin was recommended for severe disease.[2] Due to the differences in treatment recommendations, patients treated with vancomycin at baseline were inherently different than those treated with metronidazole, and at a higher baseline risk of poor outcomes. We used restriction and propensity score matching in an attempt to reduce this confounding bias. Facility was included in the propensity score as there is no national VA policy for the treatment of CDI, and CDI treatment decisions could vary by facility. While our propensity score included all observed confounders related to the use of metronidazole and vancomycin in our study population, there is the potential for residual confounding due to unknown factors and known but unmeasurable factors, such as cytokine responses to CDI. 
Due to the small sample size in the propensity score matched analysis, random error may have impacted the observed results.

Our findings among a national cohort of Veterans with an initial episode of mild CDI provide clinicians guidance on patients in whom metronidazole therapy may still be considered. Age was the only predictor of success identified and among patients aged $\leq 65$ years we found no difference between metronidazole compared with vancomycin on risk of 30-day all-cause mortality, CDI recurrence, or a composite of the two outcomes. Other factors, such as a primary diagnosis of CDI on hospital admission, severe underlying comorbidities, and hypoalbuminemia were associated with failure and in patients with these conditions, alternative therapy with vancomycin or fidaxomicin should be considered. 


\section{NOTES}

\section{Potential conflicts of interest disclosure:}

Haley Appaneal is supported in part by a Career Development Award, Department of Veterans Affairs, and has received research funding from Merck. Aisling Caffrey has received research funding from Pfizer, Merck, and The Medicines Company. Kerry LaPlante has received research funding or acted as a scientific advisor for Allergan, Merck, Nabriva, Ocean Spray, Paratek, Pfizer, Tetraphase, and The Medicines Company.

\section{Acknowledgements:}

The views expressed are those of the authors and do not necessarily reflect the position or policy of the United

States Department of Veterans Affairs. This material is based upon work supported, in part, by the Office of Research and Development, Department of Veterans Affairs. We appreciate the assistance of Sanja Avramovic, PhD and Farrokh Alemi, PhD from George Mason University with data generation.

\section{Funding:}

This work was supported, in part, by a grant from Merck. The funding source did not have any involvement in the collection, analysis, or interpretation of data; in the writing of the report; or in the decision to submit the article for publication. 


\section{References}

1. Magill SS, Edwards JR, Bamberg W, et al. Multistate point-prevalence survey of health care-associated infections. The New England journal of medicine 2014; 370(13): 1198-208.

2. Cohen SH, Gerding DN, Johnson S, et al. Clinical practice guidelines for Clostridium difficile infection in adults: 2010 update by the society for healthcare epidemiology of America (SHEA) and the infectious diseases society of America (IDSA). Infect Control Hosp Epidemiol 2010; 31(5): 431-55.

3. McDonald LC, Gerding DN, Johnson S, et al. Clinical Practice Guidelines for Clostridium difficile Infection in Adults and Children: 2017 Update by the Infectious Diseases Society of America (IDSA) and Society for Healthcare Epidemiology of America (SHEA). Clin Infect Dis 2018.

4. Johnson S, Louie TJ, Gerding DN, et al. Vancomycin, metronidazole, or tolevamer for Clostridium difficile infection: results from two multinational, randomized, controlled trials. Clin Infect Dis 2014; 59(3): 34554.

5. Zar FA, Bakkanagari SR, Moorthi KM, Davis MB. A comparison of vancomycin and metronidazole for the treatment of Clostridium difficile-associated diarrhea, stratified by disease severity. Clin Infect Dis 2007; 45(3): 302-7.

6. Stevens VW, Nelson RE, Schwab-Daugherty EM, et al. Comparative Effectiveness of Vancomycin and Metronidazole for the Prevention of Recurrence and Death in Patients With Clostridium difficile Infection. JAMA Intern Med 2017; 177(4): 546-53.

7. Isaac S, Scher JU, Djukovic A, et al. Short- and long-term effects of oral vancomycin on the human intestinal microbiota. J Antimicrob Chemother 2017; 72(1): 128-36.

8. Fabre V, Dzintars K, Avdic E, Cosgrove SE. Role of Metronidazole in Mild Clostridium difficile Infections. Clin Infect Dis 2018.

9. Appaneal HJ, Caffrey AR, Beganovic M, Avramovic S, LaPlante KL. Predictors of Mortality Among a National Cohort of Veterans With Recurrent Clostridium difficile Infection. Open Forum Infectious Diseases 2018/08/01.

10. Eyre DW, Walker AS, Wyllie D, et al. Predictors of first recurrence of Clostridium difficile infection: implications for initial management. Clin Infect Dis 2012; 55 Suppl 2: S77-87.

11. Beinortas T, Burr NE, Wilcox MH, Subramanian V. Comparative efficacy of treatments for Clostridium difficile infection: a systematic review and network meta-analysis. Lancet Infect Dis 2018.

12. Agency for Healthcare Research and Quality. Clinical Classifications Software (CCS), Healthcare Cost and Utilization Project (HCUP). Rockville, MD: Agency for Healthcare Research and Quality; 2015. http://www.hcup-us.ahrq.gov/toolssoftware/ccs/ccs.jsp.

13. Kassam Z, Cribb Fabersunne C, Smith MB, et al. Clostridium difficile associated risk of death score (CARDS): a novel severity score to predict mortality among hospitalised patients with $\mathrm{C}$. difficile infection. Aliment Pharmacol Ther 2016; 43(6): 725-33.

14. Garey KW, Sethi S, Yadav Y, DuPont HL. Meta-analysis to assess risk factors for recurrent Clostridium difficile infection. J Hosp Infect 2008; 70(4): 298-304.

15. Abou Chakra CN, Pepin J, Sirard S, Valiquette L. Risk factors for recurrence, complications and mortality in Clostridium difficile infection: a systematic review. PLoS One 2014; 9(6): e98400. 
16. Deshpande A, Pasupuleti V, Thota $P$, et al. Risk factors for recurrent Clostridium difficile infection: a systematic review and meta-analysis. Infect Control Hosp Epidemiol 2015; 36(4): 452-60.

17. Surawicz CM, Brandt LJ, Binion DG, et al. Guidelines for diagnosis, treatment, and prevention of Clostridium difficile infections. Am J Gastroenterol 2013; 108(4): 478-98; quiz 99.

18. Keddis MT, Khanna S, Noheria A, Baddour LM, Pardi DS, Qian Q. Clostridium difficile infection in patients with chronic kidney disease. Mayo Clinic proceedings 2012; 87(11): 1046-53.

19. Debast SB, Bauer MP, Kuijper EJ, Committee. European Society of Clinical Microbiology and Infectious Diseases: update of the treatment guidance document for Clostridium difficile infection. Clinical microbiology and infection : the official publication of the European Society of Clinical Microbiology and Infectious Diseases 2014; 20 Suppl 2: 1-26.

20. Hosmer DW, Lemeshow S. Applied Logistic Regression. 2nd ed. New York, NY: John Wiley \& Sons, Inc, 2000.

21. Vaughan AS, Kelley CF, Luisi N, del Rio C, Sullivan PS, Rosenberg ES. An application of propensity score weighting to quantify the causal effect of rectal sexually transmitted infections on incident HIV among men who have sex with men. BMC Med Res Methodol 2015; 15: 25.

22. Stuart EA. Matching methods for causal inference: A review and a look forward. Stat Sci 2010; 25(1): 121.

23. Asempa TE, Nicolau DP. Clostridium difficile infection in the elderly: an update on management. Clin Interv Aging 2017; 12: 1799-809.

24. Takahashi M, Mori N, Bito S. Multi-institution case-control and cohort study of risk factors for the development and mortality of Clostridium difficile infections in Japan. BMJ Open 2014; 4(9): e005665.

25. Khanna S, Gupta A, Baddour LM, Pardi DS. Epidemiology, outcomes, and predictors of mortality in hospitalized adults with Clostridium difficile infection. Intern Emerg Med 2016; 11(5): 657-65.

26. Vardakas KZ, Polyzos KA, Patouni K, Rafailidis PI, Samonis G, Falagas ME. Treatment failure and recurrence of Clostridium difficile infection following treatment with vancomycin or metronidazole: a systematic review of the evidence. Int J Antimicrob Agents 2012; 40(1): 1-8.

27. Majors D, Ellis P. Risk Factors for Recurrent Clostridium difficile Infections and Strategies to Decrease Readmissions in a Community Hospital. Hosp Pharm 2015; 50(11): 1003-10.

28. Collins CE, Ayturk MD, Anderson FA, Jr., Santry HP. Predictors and outcomes of readmission for Clostridium difficile in a national sample of medicare beneficiaries. J Gastrointest Surg 2015; 19(1): 8899; discussion

29. Kelly CP. Can we identify patients at high risk of recurrent Clostridium difficile infection? Clinical microbiology and infection : the official publication of the European Society of Clinical Microbiology and Infectious Diseases 2012; 18 Suppl 6: 21-7.

30. Eze P, Balsells E, Kyaw $\mathrm{MH}$, Nair H. Risk factors for Clostridium difficile infections - an overview of the evidence base and challenges in data synthesis. J Glob Health 2017; 7(1): 010417.

31. Gomez-Simmonds A, Kubin CJ, Furuya EY. Comparison of 3 severity criteria for Clostridium difficile infection. Infect Control Hosp Epidemiol 2014; 35(2): 196-9.

32. Mulki R, Baumann AJ, Alnabelsi T, et al. Body mass index greater than 35 is associated with severe Clostridium difficile infection. Aliment Pharmacol Ther 2017; 45(1): 75-81. 
33. Nathanson BH, Higgins TL, McGee WT. The dangers of extreme body mass index values in patients with Clostridium difficile. Infection 2017; 45(6): 787-93.

34. Flegal KM, Graubard BI, Williamson DF, Gail MH. Excess deaths associated with underweight, overweight, and obesity. JAMA 2005; 293(15): 1861-7.

35. Siegfried J, Dubrovskaya Y, Flagiello T, et al. Initial Therapy for Mild to Moderate Clostridium difficile Infection:Exploring the Role of Oral Metronidazole Versus Vancomycin in 168 Hospitalized Patients. Infectious Diseases in Clinical Practice 2016; 24(4): 210-6.

36. Nguyen CT, Li J, Anders S, Garcia-Diaz J, Staffeld-Coit C, Hand J. Comparison of outcomes with vancomycin or metronidazole for mild-to-moderate Clostridium difficile associated diarrhea among solid organ transplant recipients: A retrospective cohort study. Transpl Infect Dis 2018; 20(3): e12867.

37. Rupnik M, Wilcox MH, Gerding DN. Clostridium difficile infection: new developments in epidemiology and pathogenesis. Nature reviews Microbiology 2009; 7(7): 526-36.

38. Aas J, Gessert CE, Bakken JS. Recurrent Clostridium difficile colitis: case series involving 18 patients treated with donor stool administered via a nasogastric tube. Clin Infect Dis 2003; 36(5): 580-5.

39. Cornely OA, Crook DW, Esposito R, et al. Fidaxomicin versus vancomycin for infection with Clostridium difficile in Europe, Canada, and the USA: a double-blind, non-inferiority, randomised controlled trial. Lancet Infect Dis 2012; 12(4): 281-9.

40. Larentis DZ, Rosa RG, Dos Santos RP, Goldani LZ. Outcomes and Risk Factors Associated with Clostridium difficile Diarrhea in Hospitalized Adult Patients. Gastroenterol Res Pract 2015; 2015: 346341. 
Table 1. Baseline characteristics among a national cohort of Veterans with an initial episode of mild CDI treated with metronidazole with and without successful outcomes

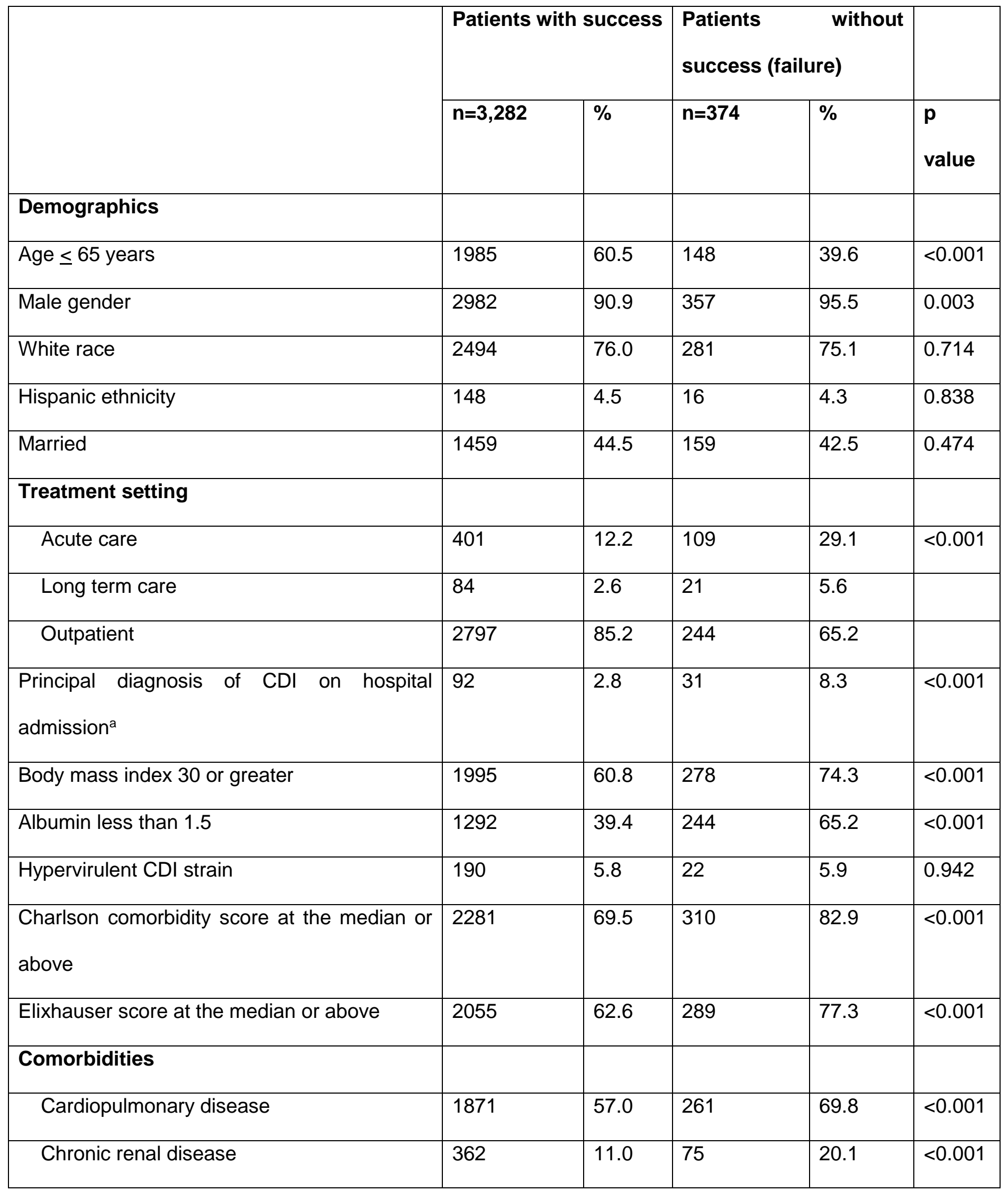




\begin{tabular}{|c|c|c|c|c|c|}
\hline Dementia & 127 & 3.9 & 22 & 5.9 & 0.062 \\
\hline Diabetes & 1108 & 33.8 & 130 & 34.8 & 0.699 \\
\hline Gastrointestinal/ nutritional disorder & 1412 & 43.0 & 175 & 46.8 & 0.164 \\
\hline Liver disease & 344 & 10.5 & 56 & 15.0 & 0.008 \\
\hline Malignancy & 620 & 18.9 & 133 & 35.6 & $<0.001$ \\
\hline Paralysis & 137 & 4.2 & 26 & 7.0 & 0.014 \\
\hline Rheumatic disease & 1263 & 38.5 & 167 & 44.7 & 0.021 \\
\hline \multicolumn{6}{|l|}{ Current acute event or infection } \\
\hline Meningitis & $<5$ & & $<5$ & & 0.277 \\
\hline Gram negative & 136 & 4.1 & 27 & 7.2 & 0.006 \\
\hline Intestinal infection & 769 & 23.4 & 148 & 39.6 & $<0.001$ \\
\hline Acute bronchitis & 12 & 0.4 & $<5$ & & 0.625 \\
\hline Pneumonia & 121 & 3.7 & 35 & 9.4 & $<0.001$ \\
\hline Septicemia & 100 & 3.0 & 27 & 7.2 & $<0.001$ \\
\hline Bacteremia & 46 & 1.4 & 10 & 2.7 & 0.058 \\
\hline Shock & 13 & 0.4 & 7 & 1.9 & 0.003 \\
\hline Skin and soft tissue & 198 & 6.0 & 45 & 12.0 & 0.001 \\
\hline MRSA & 18 & 0.5 & 8 & 2.1 & 0.003 \\
\hline Pseudomonas & 20 & 0.6 & 6 & 1.6 & 0.043 \\
\hline Urinary tract infection & 167 & 5.1 & 42 & 11.2 & $<0.001$ \\
\hline Respiratory failure & 64 & 2.0 & 36 & 9.6 & $<0.001$ \\
\hline Acute renal failure & 171 & 5.2 & 50 & 13.4 & $<0.001$ \\
\hline Fever of unknown origin & 76 & 2.3 & 6 & 1.6 & 0.379 \\
\hline \multicolumn{6}{|l|}{ Previous acute event or infection } \\
\hline Meningitis & 11 & 0.3 & $<5$ & & 1.00 \\
\hline Gram negative & 155 & 4.7 & 26 & 7.0 & 0.060 \\
\hline Influenza & 24 & 0.7 & $<5$ & & 0.752 \\
\hline
\end{tabular}




\begin{tabular}{|c|c|c|c|c|c|}
\hline Intestinal infection & 883 & 26.9 & 173 & 46.3 & $<0.001$ \\
\hline Acute bronchitis & 177 & 5.4 & 12 & 3.2 & 0.071 \\
\hline Pneumonia & 382 & 11.6 & 87 & 23.3 & $<0.001$ \\
\hline Septicemia & 246 & 7.5 & 62 & 16.6 & $<0.001$ \\
\hline Bacteremia & 118 & 3.6 & 22 & 5.9 & 0.029 \\
\hline Shock & 40 & 1.2 & 16 & 4.3 & $<0.001$ \\
\hline Skin and soft tissue & 692 & 21.1 & 106 & 28.3 & $<0.001$ \\
\hline MRSA & 78 & 2.4 & 16 & 4.3 & 0.028 \\
\hline Pseudomonas & 51 & 1.6 & 9 & 2.4 & 0.219 \\
\hline Urinary tract infection & 515 & 15.7 & 93 & 24.9 & $<0.001$ \\
\hline Respiratory failure & 164 & 5.0 & 56 & 15.0 & $<0.001$ \\
\hline \multicolumn{6}{|l|}{ Healthcare exposures } \\
\hline Surgery, during CDI treatment & 133 & 4.1 & 23 & 6.1 & 0.057 \\
\hline $\begin{array}{l}\text { VA Hospitalization or long-term care, prior } \\
90 \text { days }\end{array}$ & 1152 & 35.1 & 241 & 64.4 & $<0.001$ \\
\hline \multicolumn{6}{|l|}{ Medication exposures } \\
\hline $\begin{array}{l}\text { Non-CDI antibiotic use, } 30 \text { days before or } \\
\text { during CDI treatment }\end{array}$ & 2082 & 63.4 & 277 & 74.1 & $<0.001$ \\
\hline $\begin{array}{l}\text { Gastric acid suppressant use, } 7 \text { days before } \\
\text { or during CDI treatment }\end{array}$ & 1123 & 34.2 & 189 & 50.5 & $<0.001$ \\
\hline $\begin{array}{l}\text { Immunosuppressant use, } 7 \text { days before or } \\
\text { during CDI treatment }\end{array}$ & 192 & 5.9 & 61 & 16.3 & $<0.001$ \\
\hline $\begin{array}{l}\text { Probiotic use, } 7 \text { days before or during CDI } \\
\text { treatment }\end{array}$ & 110 & 3.4 & 43 & 11.5 & $<0.001$ \\
\hline
\end{tabular}

$\mathrm{CDI}=$ Clostridium difficile infection; $\mathrm{IQR}=$ interquartile range; $\mathrm{SD}=$ standard deviation 
Success was defined as absence of death from any cause or CDI recurrence within 30 days from the end of treatment of the initial episode. Patients with success were those who experienced success at day 30 , and those without success (failures) were those who died or recurred within 30 days from end of treatment.

${ }^{\text {aA }}$ principal diagnosis of CDI on hospital admission was compared to those without a principal diagnosis of CDI on hospital admission/ outpatients. 
Table 2. Independent predictors of success and failure at $\mathbf{3 0}$ days post-CDI treatment with metronidazole monotherapy

\begin{tabular}{|c|c|c|c|}
\hline Predictor & $\begin{array}{l}\text { Adjusted Odds } \\
\text { ratio }\end{array}$ & $\begin{array}{l}\text { Lower } \quad 95 \% \\
\text { confidence limit }\end{array}$ & $\begin{array}{l}\text { Upper } \quad 95 \% \\
\text { confidence limit }\end{array}$ \\
\hline \multicolumn{4}{|c|}{ Predictors of success - absence of mortality or CDI recurrence at day 30 post treatment (odds ratio > } \\
\hline Age $\leq 65$ years & 1.63 & 1.29 & 2.06 \\
\hline \multicolumn{4}{|c|}{ Predictors of failure - mortality or CDI recurrence within 30 post treatment (odds ratio $>1$ ) } \\
\hline $\begin{array}{l}\text { Probiotic exposure, } 7 \text { days prior or during } \\
\text { CDI treatment }\end{array}$ & 0.33 & 0.22 & 0.49 \\
\hline Current respiratory failure & 0.34 & 0.22 & 0.54 \\
\hline $\begin{array}{l}\text { VA hospital or long-term care exposure, } \\
90 \text { days prior }\end{array}$ & 0.52 & 0.41 & 0.67 \\
\hline Hypoalbuminemia ${ }^{a}$ & 0.53 & 0.42 & 0.68 \\
\hline $\begin{array}{l}\text { Principal diagnosis of CDI on hospital } \\
\text { admission }\end{array}$ & 0.54 & 0.34 & 0.85 \\
\hline Malignancy & 0.60 & 0.47 & 0.77 \\
\hline Body mass index greater $\geq 30 \mathrm{~kg} / \mathrm{m}^{2}$ & 0.74 & 0.57 & 0.96 \\
\hline Current intestinal infection & 0.74 & 0.58 & 0.95 \\
\hline
\end{tabular}

$\mathrm{CDI}=$ Clostridium difficile infection

The adjusted odds ratios are estimated from multivariable analysis of the data. The final multivariable unconditional logistic regression model included all variables in Table 2. Success was defined as absence of death from any cause or CDI recurrence within 30 days from the end of treatment of the initial episode. Those with success were those who experienced success at day 30, and those without success (failures) were those who died or recurred within 30 days from end of treatment. Thus, variables with an odds ratio greater than one were independent predictors of success, and those with an odds ratio less than one were predictors of failure. 
aHypoalbuminemia was defined as an albumin level $<1.5 \mathrm{mg} / \mathrm{dL}$ as compared to level above or missing. 
Table 3. Patient characteristics of patients aged 65 years or under with mild disease treated with metronidazole or vancomycin: Unmatched and matched cohorts

\begin{tabular}{|c|c|c|c|c|c|c|c|c|c|c|c|c|}
\hline & \multicolumn{6}{|c|}{ Unmatched cohort } & \multicolumn{6}{|c|}{ Matched cohort } \\
\hline & \multicolumn{2}{|c|}{$\begin{array}{l}\text { Met } \\
(n=2,133)\end{array}$} & \multicolumn{2}{|c|}{$\begin{array}{l}\text { Van } \\
(n=118)\end{array}$} & \multirow[b]{2}{*}{$\begin{array}{l}\mathbf{P} \\
\text { value }\end{array}$} & \multirow[b]{2}{*}{ SB } & \multicolumn{2}{|c|}{$\begin{array}{l}\text { Met } \\
(n=115)\end{array}$} & \multicolumn{2}{|c|}{$\begin{array}{l}\text { Van } \\
(n=115)\end{array}$} & \multirow{2}{*}{\begin{tabular}{|l} 
\\
$\mathbf{P}$ \\
value
\end{tabular}} & \multirow{2}{*}{\begin{tabular}{|l|} 
\\
SB \\
\end{tabular}} \\
\hline & $\mathbf{n}$ & $\%$ & $\mathbf{n}$ & $\%$ & & & $n$ & $\%$ & $\mathbf{n}$ & $\%$ & & \\
\hline \multicolumn{13}{|l|}{ Demographics } \\
\hline $\begin{array}{l}\text { Age, years, median, } \\
\text { IQR }\end{array}$ & 57 & $\begin{array}{l}47- \\
62\end{array}$ & 59 & $\begin{array}{l}51- \\
64\end{array}$ & 0.003 & 0.23 & 59 & $\begin{array}{l}52- \\
63\end{array}$ & 59 & $\begin{array}{l}51- \\
64\end{array}$ & 0.436 & 0.04 \\
\hline Male gender & 1853 & 86.9 & 105 & 89.0 & 0.507 & 0.06 & 101 & 87.8 & 103 & 89.6 & 0.677 & 0.05 \\
\hline White race & 1576 & 73.9 & 82 & 69.5 & 0.291 & 0.10 & 77 & 67 & 81 & 70.4 & 0.570 & 0.08 \\
\hline Hispanic ethnicity & 114 & 5.3 & 7 & 5.9 & 0.783 & 0.03 & 7 & 6.1 & 7 & 6.1 & 1.000 & 0.00 \\
\hline Married & 857 & 40.2 & 39 & 33.1 & 0.124 & 0.15 & 32 & 27.8 & 39 & 33.9 & 0.318 & 0.13 \\
\hline \multicolumn{13}{|l|}{ Treatment setting } \\
\hline Acute care & 207 & 9.7 & 34 & 28.8 & & 0.50 & 38 & 33 & 33 & 28.7 & & 0.09 \\
\hline Long term care & 35 & 1.6 & 9 & 7.6 & & 0.29 & 7 & 6.1 & 7 & 6.1 & & 0.00 \\
\hline Outpatient & 1891 & 88.7 & 75 & 63.6 & $<0.001$ & 0.62 & 70 & 60.9 & 75 & 65.2 & 0.769 & 0.00 \\
\hline \multicolumn{13}{|l|}{ Region } \\
\hline Midwest & 532 & 24.9 & 19 & 16.1 & & 0.22 & 15 & 14.3 & 18 & 17.1 & & 0.05 \\
\hline Northeast & 233 & 10.9 & 17 & 14.4 & & 0.10 & 17 & 16.2 & 15 & 14.3 & & 0.02 \\
\hline West & 534 & 25.0 & 39 & 33.1 & & 0.18 & 40 & 38.1 & 31 & 29.5 & & 0.11 \\
\hline South & 834 & 39.1 & 43 & 36.4 & 0.050 & 0.05 & 33 & 31.4 & 41 & 39.0 & 0.824 & 0.09 \\
\hline \multicolumn{13}{|l|}{ Year } \\
\hline 2010 & 247 & 11.6 & 3 & 2.5 & & 0.36 & 5 & 4.3 & 3 & 2.6 & & 0.10 \\
\hline 2011 & 456 & 21.4 & 31 & 26.3 & & 0.12 & 20 & 17.4 & 30 & 26.1 & & 0.21 \\
\hline
\end{tabular}




\begin{tabular}{|c|c|c|c|c|c|c|c|c|c|c|c|c|}
\hline 2012 & 469 & 22.0 & 24 & 20.3 & & 0.04 & 31 & 27 & 24 & 20.9 & & 0.14 \\
\hline 2013 & 439 & 20.6 & 30 & 25.4 & & 0.12 & 28 & 24.3 & 28 & 24.3 & & 0.00 \\
\hline 2014 & 522 & 24.5 & 30 & 25.4 & $<0.028$ & 0.02 & 31 & 27.0 & 30 & 26.1 & 0.492 & 0.00 \\
\hline $\begin{array}{l}\text { Principal diagnosis of } \\
\text { CDI }\end{array}$ & 46 & 2.2 & 7 & 5.9 & 0.019 & 0.19 & 7 & 6.1 & 6 & 5.2 & 0.775 & 0.04 \\
\hline $\begin{array}{l}\text { Body mass index } 30 \text { or } \\
\text { greater }\end{array}$ & 1190 & 55.8 & 85 & 72.0 & $<0.001$ & 0.34 & 78 & 67.8 & 82 & 71.3 & 0.5667 & 0.08 \\
\hline Albumin less than 1.5 & 754 & 35.3 & 70 & 59.3 & $<0.001$ & 0.49 & 57 & 49.6 & 67 & 58.3 & 0.186 & 0.18 \\
\hline Hypervirulent strain CDI & 111 & 5.2 & 11 & 9.3 & 0.054 & 0.16 & 14 & 12.2 & 11 & 9.6 & 0.525 & 0.08 \\
\hline $\begin{array}{l}\text { Treatment duration, } \\
\text { days, median (IQR) }\end{array}$ & 11 & $\begin{array}{l}11- \\
11\end{array}$ & 11 & $\begin{array}{l}11- \\
12\end{array}$ & $<0.001$ & 0.31 & 11 & $\begin{array}{l}11- \\
12\end{array}$ & 11 & $\begin{array}{l}11- \\
12\end{array}$ & 0.792 & 0.03 \\
\hline $\begin{array}{l}\text { Charlson comorbidity } \\
\text { score at the median or } \\
\text { above }\end{array}$ & 1298 & 60.9 & 92 & 78.0 & $<0.001$ & 0.38 & 84 & 73 & 89 & 77.4 & 0.445 & 0.10 \\
\hline $\begin{array}{l}\text { Elixhauser score at the } \\
\text { median or above }\end{array}$ & 1215 & 57.0 & 90 & 76.3 & $<0.001$ & 0.42 & 89 & 77.4 & 87 & 75.7 & 0.756 & 0.04 \\
\hline \multicolumn{13}{|l|}{ Comorbidities } \\
\hline $\begin{array}{l}\text { Cardiopulmonary } \\
\text { disease }\end{array}$ & 983 & 46.1 & 73 & 61.9 & $<0.001$ & 0.32 & 69 & 60 & 72 & 62.6 & 0.685 & 0.05 \\
\hline Chronic renal disease & 173 & 8.1 & 14 & 11.9 & 0.150 & 0.13 & 9 & 7.8 & 13 & 11.3 & 0.370 & 0.12 \\
\hline Dementia & 14 & 0.7 & $<5$ & & 0.203 & 0.10 & $<5$ & & $<5$ & & 1.00 & 0.06 \\
\hline Diabetes & 625 & 29.3 & 34 & 28.8 & 0.910 & 0.01 & 33 & 28.7 & 34 & 29.6 & 0.885 & 0.02 \\
\hline $\begin{array}{l}\text { Gastrointestinal/ } \\
\text { nutritional disorder }\end{array}$ & 918 & 43.0 & 51 & 43.2 & 0.969 & 0.00 & 56 & 48.7 & 51 & 44.3 & 0.509 & 0.09 \\
\hline Liver disease & 299 & 14.0 & 23 & 19.5 & 0.098 & 0.15 & 18 & 15.7 & 22 & 19.1 & 0.487 & 0.09 \\
\hline Malignancy & 290 & 13.6 & 23 & 19.5 & 0.072 & 0.16 & 17 & 14.8 & 23 & 20 & 0.297 & 0.14 \\
\hline
\end{tabular}




\begin{tabular}{|c|c|c|c|c|c|c|c|c|c|c|c|c|}
\hline Paralysis & 82 & 3.8 & 9 & 7.6 & 0.052 & 0.16 & 7 & 6.1 & 9 & 7.8 & 0.604 & 0.07 \\
\hline Rheumatic disease & 745 & 34.9 & 54 & 45.8 & 0.017 & 0.22 & 49 & 42.6 & 52 & 45.2 & 0.690 & 0.05 \\
\hline \multicolumn{13}{|l|}{$\begin{array}{l}\text { Acute events or } \\
\text { infections }\end{array}$} \\
\hline $\begin{array}{l}\text { Current acute renal } \\
\text { failure }\end{array}$ & 83 & 3.9 & 9 & 7.6 & 0.055 & 0.16 & 6 & 5.2 & 9 & 7.8 & 0.423 & 0.11 \\
\hline $\begin{array}{l}\text { Current fever of } \\
\text { unknown origin }\end{array}$ & 52 & 2.4 & $<5$ & & 1.0 & 0.05 & $<5$ & & $<5$ & & 1.00 & 0.06 \\
\hline Current infection & 651 & 30.5 & 62 & 52.5 & $<0.001$ & 0.46 & 64 & 55.7 & 60 & 52.2 & 0.597 & 0.07 \\
\hline $\begin{array}{l}\text { Current septicemia/ } \\
\text { bacteremia / shock }\end{array}$ & 58 & 2.7 & 12 & 10.2 & $<0.001$ & 0.31 & 7 & 6.1 & 11 & 9.6 & 0.326 & 0.13 \\
\hline Previous infection & 1085 & 50.9 & 91 & 77.1 & $<0.001$ & 0.57 & 90 & 78.3 & 88 & 76.5 & 0.753 & 0.04 \\
\hline $\begin{array}{l}\text { Previous septicemia/ } \\
\text { bacteremia / shock }\end{array}$ & 152 & 7.1 & 21 & 17.8 & $<0.001$ & 0.33 & 18 & 15.7 & 20 & 17.4 & 0.723 & 0.05 \\
\hline \multicolumn{13}{|l|}{ Healthcare exposures } \\
\hline $\begin{array}{l}\text { Surgery, } 30 \text { days } \\
\text { before or during CDI } \\
\text { treatment }\end{array}$ & 79 & 3.7 & 10 & 8.5 & 0.024 & 0.20 & 10 & 8.7 & 9 & 7.8 & 0.811 & 0.03 \\
\hline $\begin{array}{l}\text { VA Hospitalization or } \\
\text { long-term care, prior } 90 \\
\text { days }\end{array}$ & 680 & 31.9 & 74 & 62.7 & $<0.001$ & 0.65 & 72 & 62.6 & 72 & 62.6 & 1.00 & 0.00 \\
\hline \multicolumn{13}{|l|}{ Medication exposures } \\
\hline $\begin{array}{l}\text { Non-CDI antibiotic } \\
\text { use, } 30 \text { days before or } \\
\text { during CDI treatment }\end{array}$ & 1320 & 61.9 & 77 & 65.3 & 0.463 & 0.07 & 65 & 56.5 & 75 & 65.2 & 0.177 & 0.18 \\
\hline $\begin{array}{l}\text { Gastric acid } \\
\text { suppressant use, } 7 \text { days }\end{array}$ & 704 & 33.0 & 59 & 50.0 & $<0.001$ & 0.35 & 57 & 49.6 & 58 & 50.4 & 0.895 & 0.02 \\
\hline
\end{tabular}




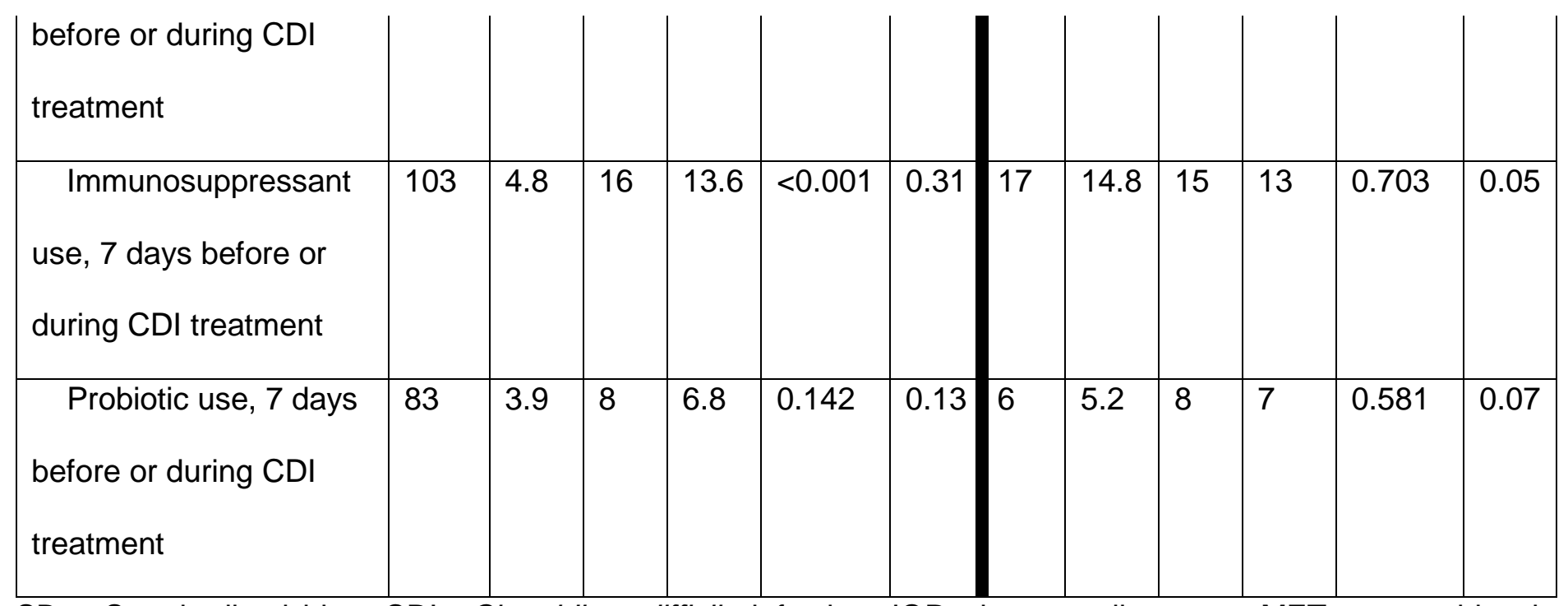

$\mathrm{SB}$ = Standardized bias; $\mathrm{CDI}=$ Clostridium difficile infection; $\mathrm{IQR}=$ interquartile range; $\mathrm{MET}=$ metronidazole treatment; VAN= vancomycin treatment

Data in the $\mathrm{n} \%$ columns represent the number and percent, unless otherwise indicated. 
Table 4. Unadjusted and propensity score matched hazard ratios for the effect of metronidazole versus vancomycin on outcomes among patients aged 65 years or under with an initial episode of mild CDI

\begin{tabular}{|c|c|c|c|c|c|c|}
\hline Clinical Outcome & $\begin{array}{l}\mathbf{N} \text { event/ } \mathbf{N} \\
\text { met }\end{array}$ & $\begin{array}{l}\mathbf{N} \text { event/ } \\
\mathbf{N} \text { van }\end{array}$ & $\begin{array}{l}\text { Unadjusted HR } \\
(95 \% \mathrm{Cl})\end{array}$ & $\begin{array}{l}\mathbf{N} / \mathbf{N} \\
\text { met }\end{array}$ & $\begin{array}{l}\mathbf{N} \text { events/ } \\
\mathbf{N} \text { van }\end{array}$ & $\begin{array}{l}\text { Matched HR } \\
(95 \% \mathrm{Cl})\end{array}$ \\
\hline All-cause mortality & $33 / 2133$ & $8 / 118$ & $0.22(0.10-0.48)$ & $2 / 115$ & $8 / 115$ & $\begin{array}{l}0.29 \quad(0.06- \\
1.38)\end{array}$ \\
\hline Recurrence & $116 / 2133$ & $15 / 118$ & $0.42(0.24-0.72)$ & $8 / 115$ & $14 / 115$ & $\begin{array}{l}0.62 \quad(0.26- \\
1.49)\end{array}$ \\
\hline $\begin{array}{l}\text { Failure (mortality or } \\
\text { recurrence) }\end{array}$ & $148 / 2133$ & $23 / 118$ & $0.33(0.21-0.51)$ & $10 / 115$ & $22 / 115$ & $\begin{array}{l}0.50 \quad(0.23- \\
1.07)\end{array}$ \\
\hline
\end{tabular}

$\mathrm{Cl}=$ confidence interval; $\mathrm{HR}=$ hazard ratio; $\mathrm{N}=$ number; Van- = Vancomycin treated patients; Met = Metronidazole treated patients.

Propensity score matched within 0.01 caliper.

The propensity was derived from an unconditional logistic regression model controlling for age, region, Charlson comorbidity index, Elixhauser score, BMI, race, ethnicity, marital status, principal diagnosis of CDI, albumin, CDI treatment duration, gender, gastric acid suppressant use, antibiotic use, probiotic use, immunosuppressant use, VA long-term care or hospital exposure prior 90 days, cardiopulmonary disease, gastrointestinal /nutritional disorder, liver disease, diabetes, rheumatic disease, chronic renal disease, dementia, current acute renal failure, HIV, current fever, surgery, current sepsis/shock/ bacteremia, history of sepsis/shock/ bacteremia, history of infection, current infection, treatment setting, virulent strain. 